\title{
Feedback in Learning: Screencasts as Tools to Support Instructor Feedback to Students and the Issue of Learning from Feedback Given to Other Learners
}

\author{
Joachim Griesbaum
}

\begin{abstract}
Feedback can be seen as a key component to support learning. In particular, elaborate feedback that makes specific information about learning outcomes available and provides hints for improvements can be seen as worthwhile but is also costly. In this context, this paper discusses feedback in learning and screencasts as technological tools to support the provision of instructor-given feedback. The results of two case studies are presented. In the case studies, screencasts were employed as a tool to provide feedback on the results of students' group work. These feedback screencasts were available for the group members and also all course participants. On this basis, the question of whether students learn from feedback given to other learners is discussed.
\end{abstract}

Index Terms - Feedback, podcast, screencast.

\section{INTRODUCTION}

Feedback can be seen as an important instructional tool in learning. The beneficial effects of receiving feedback for learners are beyond dispute. Feedback affects the motivation of the learners as well as their cognition and self-regulation ([1]-[3]). Although there is much research on the topic (cp. [1] for an overview), learner surveys indicate that the provision of feedback in practice often does not perform well [2]. At the same time, researchers are investigating ways to employ information and communication technology (ICT) to improve feedback in teaching.

The topical area of feedback in education is characterized by a large volume of research, which includes such diverse topics as interactive feedback systems (e.g., [4]), automatic assessments and feedback (e.g., [5]), peer assessment (e.g., [6], [7]), and audio- and screencasts as tools to provide feedback (e.g., [8]-[10]).

The focus of this paper is on the latter topic. The aim of this investigation is to enrich current research with results from two case studies. In these case studies, screencasts are employed to provide feedback on the results of cooperative group work. First, the investigation analyses the acceptance and assessment of such screencast feedback on the part of the directly addressed learners in the corresponding group. Furthermore, this paper also aims to provide insight on if such screencast feedback can serve as a viable tool to initiate learning on an expanded social level. This means that this study also investigates whether those screencasts are also used and assessed as helpful by students who are not directly

Manuscript received May 12, 2016; September 28, 2016.

The author is with University of Hildesheim, Germany (e-mail: joachim.griesbaum@web.de). involved in the group work on which the feedback is provided. We may call such feedback usage as "learning from feedback given to others". This is a question barely addressed by current research in the field. Hence, this paper asks if such feedback screencasts which are openly provided for all participants in a course scenario are accepted by all students; the students who are directly addressed and also the other participants in the course. In addition, the usage and assessment of such screencast-based feedback are investigated.

The paper is structured as follows. It starts with a short overview on feedback in learning, its effects, and quality factors. Next, screencasts as a feedback tool are introduced. Following that, the issue of learning from feedback given to other learners is discussed. Then, the concept and methodologies of the two case studies are outlined and results are presented. The paper closes with an estimation of the educational value of the screencast configuration employed in the case studies.

\section{FEEDBACK IN LEARNING}

The beneficial effects of feedback are twofold: feedback affects the motivation of the learners as well as their cognition [3]. Feedback triggers a three-stage process on the part of the recipient. First, it directs attention to certain aspects of learning procedures or results. Second, it provides information about these phenomena. Third, it enables learners to use this information to adjust their corresponding learning behaviour. In addition to those cognitive and metacognitive aspects, feedback inspires a motivational function, stimulating learners to maintain and/or increase their efforts [11].

Ref. [1] provide a literature review of computer-based feedback and formative assessment in e-learning. According to that, one can distinguish between "Knowledge of performance (KP)" that provides feedback about learners' performance; "Knowledge of response (KR)" that gives feedback on the quality of a response; "Knowledge of correct response (KCR)", giving the correct answer or solution to an item or task; and "Elaborated feedback (EF)" that provides further information, e.g., hints, examples, or resources. Feedback can be given immediately or delayed. With regard to learning success, [1] summarize elaborate feedback as the most effective feedback form and feedback that only provides information about performance as the least effective feedback form. Learners who are given feedback immediately are more likely to recognize feedback and spend more time processing 
it. Thus, if possible, feedback should not be delayed. Regarding learner characteristics, feedback seems to be most beneficial for lesser experienced and self-confident learners. On a metacognitive level, feedback is most helpful in the stimulation of self-regulated learning behaviour if it includes cues about the reasons why answers were incorrect. In addition, elaborate feedback keeps learners more engaged in tasks and more satisfied than other feedback forms. To sum up, research suggests that educators should aim to provide timely and elaborate feedback to learners.

With regard to feedback provision and feedback perception, [2] argue that there is a gap between educators and learners. According to [2], educators typically assume that their feedback is more useful than learners believe it to be. Students report that feedback often exhibits shortcomings with regard to the amount of feedback and feedback quality. This may be caused by ignorance about feedback on the part of the learners At first glance, improving the quality of the provided feedback seems to be a feasible solution. But one has to be careful. The above mentioned research results on feedback provision, according to [1], can only serve as a rough guideline. There is no clear-cut way of providing feedback. For example, in complex learning tasks delayed feedback may allow learners to reflect on the learning process for themselves.

The line of argument in [2] goes beyond the improvement of instructor-given feedback. The authors are critical of feedback provision which is usually unidirectional and aimed at short-term learning improvements. They argue that feedback requires feedback in order to improve and that educators should also aim to foster the development of sustainable learning habits; e.g., self-regulated learning. They aim for a system in which feedback is less a ritual at the end of learning tasks but more of an encompassing system. Such a system should establish feedback as a general habit in learning, expand the social level of feedback sources, establish self- and peer-feedback as additional feedback components, and aim to provide continuous feedback. The paper is very interesting as it argues for a wider scope for the topic. It argues for an expanded view of feedback provision and feedback providers. Although the argumentation of this paper does not follow these ideas on a one-to-one basis, it also aims to expand the viewpoint on feedback provision. The focus here is on the recipients and "consumers" of feedback.

\section{SCREENCASTS AS A FEEDBACK TOOL}

Screencasts can be defined as video recordings of screen activities that are usually combined with an audio commentary. Files only containing audio can be defined as audiocasts or podcasts. Screencasts and podcasts offer unique educational benefits. In comparison to text, audio- and screencasts exhibit a higher grade of media richness [12]. Screencasts combine different modalities, thus realizing benefits as argued by the theory of multimedia learning [13]. In addition, the audio modality may create a specific kind of social presence by conveying a sense of immediacy and a more personal connection with the instructor [14] than textual resources can accomplish. Furthermore, audiocasts or audio components may be consumed in situations in which the user's visual system is focused on something different, e.g., when the user is on the move or in transit. Therefore, screencasts and audio casts have some specific attributes concerning knowledge transmission. For users, in addition to being able to consume such feedback anywhere and anytime, there may also be possible modal advantages, concerning the audio modality and the efficacy of audio-visual synchronicity [15].

Furthermore, providing elaborate oral or written feedback is a very time-consuming activity for the provider. Whereas oral feedback takes lecture time, the formulation of written feedback usually takes a comparatively longer time span. This time expenditure is not a problem per se. Nevertheless, podcast technology may offer some advantages to prepare and provide feedback. Although, the preparation of screencasts requires a certain technological infrastructure, it is reasonable to state that the hard- and software threshold for producing audio casts is rather low: a microphone and audio-recording software are sufficient (e.g., the free audacity software program). Screencasts have higher requirements. In addition to audio, the recording of screen activities is required. Like audiocasts, it is possible to produce screencasts with the help of free or open-source software. There are even free tools that only need an up-to-date browser in order to work (e.g., screencast-o-matic.com, www.screencastify.com). Thus, once the initial technological hurdles have been overcome, screencast technology can be seen as a way to reduce the required workload in order to provide feedback.

In summary, one can argue that audiocasts and screencasts may be valuable tools used to provide feedback. They alleviate feedback provision and feedback usage at the same time and may even show cognitive and motivational advantages on the part of the feedback receiver. The following case studies confirm this positive assessment.

The first case study [10] employed screencasts as a feedback tool in an online marketing course with 26 students at the University of Hildesheim in order to determine the hindrances and benefits of screencasts as a feedback tool. Screencasts were used to provide instructor feedback on the results of the students' group-work assignments. The authors state that there are some hindrances and initial costs necessary to build up a suitable podcast environment and for the instructors to become comfortable with podcast production. Nevertheless, they conclude that the technical threshold is not prohibitive for real-life teaching. In contrast, once the initial hurdles in producing screencasts are overcome, feedback-screencasts can be seen as a way to reduce instructor workload. Results from a survey at the end of the course showed a mixed picture with respect to the perception and acceptance of such a feedback method. The majority of students rated feedback-podcasts as helpful and a strong majority even assessed them as a sufficient means of receiving feedback.

In another investigation, [9] applied feedback screencasts in a business and accounting context in a Managing Finance module for first-year undergraduate business and event management students. As part of the course, students had to prepare a case-study in which pairs of students had to evaluate the viability of two projects using investment appraisal techniques. Feedback was provided during the course $\left(9^{\text {th }}\right.$ 
week) and at the end of the course $\left(12^{\text {th }}\right.$ week). Results of an online survey and focus groups show a strong preference for screencast feedback in comparison to traditional written or audio only feedback. The authors indicate that screencast feedback increased the "value placed on feedback by students". Feedback provision went smoothly, although feedback distribution was partly cumbersome due to the large file sizes (80-90 megabyte per podcast). It took 10-15 minutes to record the screencast videos. The authors state, "The speed and quality of screencasting improved progressively as the tutor became more familiar with the use of the software and voice recordings."

Ref. [8] utilized screencasts in a distance learning master course with 14 students at Sheffield Hallam University to provide feedback on students' essays. In a quasi-experimental design, students were randomly split into two groups. Each group was initially provided with either written or screencast feedback. Then, students had to complete a short questionnaire on feedback perception. After that, the students received the second type of feedback. Finally, students again had to take part in the questionnaire on feedback perception. In comparing both feedback forms, results show that feedback screencasts are perceived more positively than written feedback and that feedback screencasts may evoke "emotions more conducive to receiving and processing feedback". Visual cues and explanations seem to foster understanding. Still, written feedback is preferred in order to get a holistic overview of a document. The authors conclude that from the feedback providers' perspective, "it is quicker to capture screencasts than it is to write feedback."

As a whole, the theoretical considerations and empirical results delineated in this chapter underpin the idea that it could be worthwhile to use screencasts as a tool for feedback provision.

\section{FEEDBACK USAGE ON AN EXPANDED SOCIAL LEVEL}

Surprisingly, there is very little research on the effects of feedback given to learners on other learners. At the time of writing, the author was not able to identify a single paper directly concerned with the question of whether students learn from feedback given to others. It seems that research regarding learning from feedback is generally restricted to the directly involved stakeholders, and not expanded to higher social levels. In research, feedback is largely treated as a one-to-one relationship between feedback givers and takers.

However, the value of feedback reaches beyond that. If we take a wider discourse-oriented perspective, then we can assess feedback as a reaction to an initial discourse or activity in a learning community. From this viewpoint, contributions may be important for the individual stakeholders directly involved in the conversation, but also of value to anyone within the community. Thus, feedback can be seen as knowledge input for the whole community. Such an understanding of feedback can be connected to ideas of Knowledge-building Communities as put forward, for example, by [16]. From such a perspective, providing feedback to other learners also relates to connectivism which stresses the importance of networks and connections of and to learning resources and states that "learning and knowledge rests in diversity of opinions" [17]. The following figure illustrates this concept of feedback usage on an expanded social level.

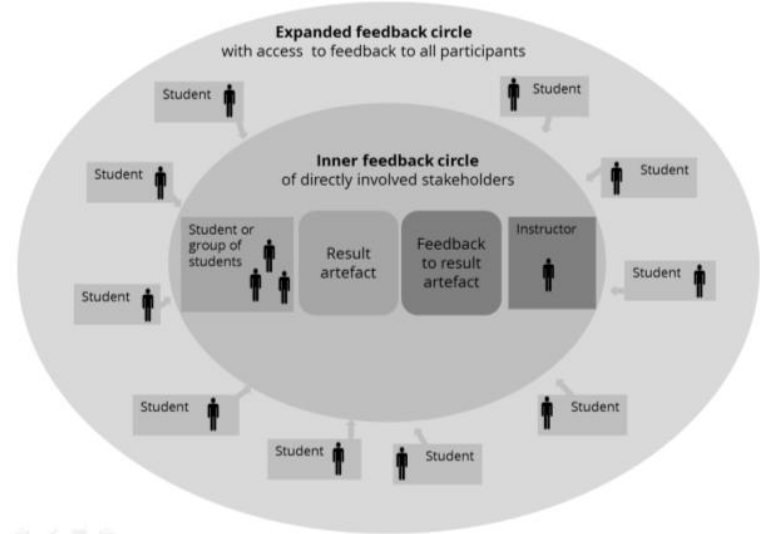

Fig. 1. Feedback usage in the inner and expanded feedback circle.

In e-learning, especially when screencasts are used as a tool to provide and deliver feedback, such a perspective seems conclusive as feedback is usually produced as an electronic artefact, which can be easily disseminated in the corresponding electronic learning systems.

Such a concept corresponds to social learning as argued above and considers feedback as general knowledge input at a class level. What are the possible benefits and drawbacks of such a feedback system? As already mentioned, it expands the knowledge base of the whole learning community. The knowledge provided with the feedback is expected to have an evaluative character, a kind of knowledge that is based on higher level thinking and can be assigned to the level "evaluate" according to Krathwohl's revision of Bloom's taxonomy [18]. Therefore, one can assume that the perception of the instructors' feedback on tasks by other students fosters procedural knowledge and also metacognitive skills on the part of the feedback users. One would hope that students are able to enhance their knowledge with regard to the usage of appropriate methods and their strategic knowledge on expectations and assessment criteria in the corresponding learning scenario to foster self-regulated learning. One possible drawback is the loss of privacy. If feedback is openly available, then the evaluative performance assessment is also visible to everyone. Maybe this is not a situation that every student would feel comfortable with. It is possible to deduce further potential benefits and drawbacks; for example, one would expect that the feedback would be more standardized. But this discussion should stop here. As there is little research in this area, the following investigation intends to carry out a basic exploration of students' acceptance and estimated value of such a feedback use. Thus, specific and pre-determined analytical criteria would not be helpful.

Summing up, the theoretical part of this paper states that:

1) Feedback is a central tool in education. Research has identified components for successful feedback: in particular, elaborate feedback that makes available specific information about learning outcomes and provides hints for improvements is seen as worthwhile.

2) Feedback provision is not enough. Students often ignore feedback. This can be partly explained by low feedback 
quality. In addition to enhancing feedback provision, one should also aim to establish feedback as a general habit in learning. Instead of relying on short-term learning improvements, educators should also foster the development of sustainable learning habits.

3) Screencasts exhibit modal and mobile features that could be worthwhile for feedback usage on the part of the learners. With regard to screencast feedback provision, a technological infrastructure is needed but the hard- and software threshold is low. Case studies that apply screencasts as a feedback tool show a high acceptance on the part of the feedback receivers and a good feasibility on part of the producers. There also seem to be positive cognitive effects, but more research is needed to get a clear picture.

4) The question of whether learners learn from feedback given to other learners is a topic that is generally unexplored. This is unfortunate; from a social learning perspective, such feedback is a valuable knowledge input.

\section{RESEARCH DESIGN}

As stated, the research interest of this study is the acceptance and assessment of screencasts as a feedback tool. A specific focus of this study is on the perception of feedback by learners not directly addressed in the expanded social level.

\section{A. Research Questions}

Research questions are structured as follows:

1) Acceptance of screencast feedback by directly addressed learners

2) Estimation of motivational effects of screencast feedback by directly addressed learners

3) Estimation of learning success of screencast feedback by directly addressed learners

4) Acceptance of screencast feedback given to other learners

5) Estimation of motivational effects of screencast feedback given to other learners

6) Estimation of learning effects of screencast feedback given to other learners

Research questions RQ1-3 aim to replicate the findings of previous studies. The news value of this investigation can be found in research questions RQ4-6.

\section{B. Case Studies}

The study was carried out in two courses at the University of Hildesheim. The author of this paper is also the instructor of the two courses.

1) An introductory course on "online marketing" in the program "B.A. in International Information Management". The course was held during the summer term of 2016. Twenty-nine students took part in the course. The goal of the course is to introduce students to the fundamental concepts of search engine and social media marketing. The course is structured into two parts a) introductory lessons, in which the instructor presents a basic overview of the concepts, and b) group work assignments, in which the students prepare detailed presentations on course topics, e.g., "keyword advertising or search engine optimization". The instructor provided feedback screencasts on the results of students' work assignments in part b). Hereafter, this course will be referred to as course A.

2) An introductory course on "e-learning and knowledge management" in the program "M.A. in International Information Management". The course was held during the summer term of 2016. Thirty-five students took part in the course. The goal of the course is to introduce students to the fundamental concepts of e-learning and knowledge management. The course structure corresponds to the structure of course A. The instructor provided feedback screencasts on the results of students' work assignments in part b). Hereafter, this course will be referred to as course $\mathrm{B}$.

\section{Provision of Screencast Feedback}

The commercial software Camtasia (www.techsmith.com/camtasia.html) was chosen for screencast production. In the screencasts, the instructor reviewed the presentation files created by the students, identified errors, provided further explanations, and gave hints for further improvements. Thus, the screencasts not only provided elaborate feedback, but also extended the knowledge of the topic provided during the lecture.

Screencast length varied from three minutes to 26 minutes. For very good group work results, the screencast length usually corresponded to only a few minutes. Screencasts on group work results that showed more room for improvement tended to be much longer. The screencasts were produced and uploaded to the learning management system (LMS) usually within an hour after the corresponding lecture was finished. Podcast production went smoothly. The technical overhead to open and save the files and upload them to the LMS corresponded usually to less than 10 minutes.

\section{Method of Investigation}

A paper-based survey was chosen as the method of investigation in both case studies. The surveys were filled out at the end of the last in-class seminar and associated with the evaluation of the course. The questionnaire consisted of 12 close-ended questions that directly asked for students' estimations on the mentioned research questions. 5-stage scales were used to measure students' answers. In addition, two open-ended questions were provided to capture students' personal assessments of feedback screencasts. 14 students from course A and 22 students from course B took part in the survey.

\section{RESULTS}

The results section is structured as follows. Firstly, the acceptance of feedback screencasts is reported (RQ1 \& RQ4). Following that, students' assessment of motivational (RQ2 \& RQ5) and cognitive effects (RQ3 \& RQ6) are described. In the analysis, data on feedback for directly involved stakeholders and feedback for all other learners on the expanded feedback circle (cp. fig. 1) are compared. 


\section{A. Acceptance of Feedback}

Students' acceptance of feedback was captured by two survey questions. One question asked if a feedback screencast to one's own group is sufficient as feedback and one question collected students' opinions on the visibility of group feedback to all learners.

Table I shows that nearly every learner viewed the feedback screencast of his/her own group work. Usage of feedback for other learner groups' work was also high, reaching a value of more than $85 \%$ in both courses. Most of the students did not view all screencasts on other group work, but viewed only some of them (2-4).

\section{TABLE I: USAGE OF FEEDBACK}

\begin{tabular}{lll}
\hline \hline & $\begin{array}{l}\text { Viewed feedback on } \\
\text { one's own group work }\end{array}$ & $\begin{array}{l}\text { Viewed feedback on other } \\
\text { group work }\end{array}$ \\
\hline Course A & $100 \%$ & $93 \%$ \\
Course B & $95 \%$ & $86 \%$ \\
\hline \hline
\end{tabular}

In addition, the vast majority of the participants in both courses agreed that the screencasts on their own group work were sufficient and that there is no need for further feedback. With regard to the visibility of the feedback screencasts for all learners, again, a majority of the survey participants in both courses approved of the idea that feedback should be visible to all learners. However, in course B a strong minority of $40 \%$ was unsure or did not agree.

In summary, the data indicates a high degree of screencast acceptance by learners directly addressed by the given feedback (RQ1). With regard to RQ2, we see a slightly different picture. One the one hand, a large number of participants viewed the feedback screencasts of other groups' work. Nevertheless, a substantial fraction of the participants either did not agree or were unsure if group feedback should be visible to all participants. Some remarks to the open-ended question "remarks and suggestions for feedback screencasts" indicate that students often differentiate between the evaluative and descriptive components of the provided feedback. Some use and see it primarily as a means to match and compare the instructor's feedback with their own estimation. They try to employ this knowledge to better align their (upcoming) group work presentation to envisioned expectations of the instructor. One comment suggested that it would be better not to mention the performance grade publicly in order to improve acceptance of such an open feedback provision. Hence, further investigations could vary and experiment with the provision and visibility of performative and descriptive feedback components for all learners.

\section{B. Motivational Effects of Feedback Screencasts}

Results with regard to the motivational effects of the employed feedback screencasts are shown in Table II.

The data indicates that screencast feedback on learners' own group work exhibits a positive impact on motivation. The corresponding values for screencast feedback on other learners' group work are near to a neutral or zero level. Thus, such a feedback provision seems to not foster motivation. In summary, data supports the notion of positive motivational effects of screencast feedback for directly addressed learners (RQ2). RQ5 has to be answered neutrally. There is no evidence that screencast feedback given to other learners fosters motivation. But the picture is not so clear here. Paired t-tests show no significant differences between the motivational effects of screencast feedback on one's own group work and on other learners' group work within both courses. There were no open remarks concerning motivational effects of feedback screencasts.

TABLE I: MotiVATIONAL EFFECTS OF FEEDBACK SCREENCASTS ${ }^{1}$

\begin{tabular}{lll}
\hline \hline & $\begin{array}{l}\text { The screencast feedback } \\
\text { on my own group work } \\
\text { fostered my learning } \\
\text { motivation }\end{array}$ & $\begin{array}{l}\text { The screencast feedback on } \\
\text { other groups' work fostered } \\
\text { my learning motivation }\end{array}$ \\
\hline Course A & $1.1(0.87)$ & $0.2(1.03)$ \\
Course B & $0.75(1.16)$ & $0.25(0.68)$ \\
\hline \hline
\end{tabular}

\section{Learning Success of Screencast Feedback}

With regard to learning success, the survey differentiated between two types of knowledge. The first type was topical knowledge on the corresponding group work task. Here, the survey asked if the provided feedback fostered the comprehension of the topic. The second type was metacognitive and/or procedural knowledge that enables learners to better handle future tasks. The following two tables show the corresponding survey data.

TABLE III: EFFECTS ON TOPICAL KNOWLEDGE OF FEEDBACK SCREENCASTS

\begin{tabular}{|c|c|c|}
\hline & $\begin{array}{l}\text { The feedback screencast } \\
\text { on my own group work } \\
\text { increased my } \\
\text { comprehension of the } \\
\text { topic }\end{array}$ & $\begin{array}{l}\text { The feedback screencast on } \\
\text { other group work increased } \\
\text { my comprehension of the } \\
\text { topic }\end{array}$ \\
\hline Course A & $0.85(0.8)$ & $0.75(0.75)$ \\
\hline Course B & $0.7(1.13)$ & $0.94(0.73)$ \\
\hline
\end{tabular}

According to Table III, feedback screencasts display positive effects on topical knowledge for both kinds of feedback usage.

TABLE IV: EFFECTS ON METACOGNITIVE AND/OR PROCEDURAL KNOWLEDGE OF FEEDBACK SCREENCASTS

\begin{tabular}{lll} 
& KNOWLEDGE OF FEEDBACK SCREENCASTS \\
\hline \hline $\begin{array}{l}\text { The feedback screencast } \\
\text { on my own group work } \\
\text { increased my ability to } \\
\text { cope with future group } \\
\text { work tasks }\end{array}$ & $\begin{array}{l}\text { The feedback screencast on } \\
\text { other group work increased } \\
\text { my ability to cope with } \\
\text { future group work tasks }\end{array}$ \\
& $\begin{array}{ll}\text { 1.33(0.89) } \\
\text { Course A }\end{array}$ & $\begin{array}{l}0.79(0.98) \\
\text { Course B }\end{array}$ \\
\hline \hline
\end{tabular}

The results in Table IV also indicate positive effects of screencast feedback on metacognitive and/or procedural knowledge. Again, learning from screencasts for other learners' group work is as worthwhile as learning from feedback to one's own work.

Overall, RQ3 (learning success of feedback screencasts by directly addressed learners) and RQ6 (learning effects of screencast feedback at an expanded social level) can both be estimated positively. Here, feedback usage on other students' group work seems to be as worthwhile as learning from feedback for the directly involved stakeholders. Again, paired

\footnotetext{
${ }^{1}$ Mean values (standard deviation) measured on a 5-stage scale ranging from -2 "does not apply at all" to +2 "fully applies".
} 
t-tests show no significant differences between both kinds of cognitive effects of screencast feedback to one's own group work and to other learners' group work within both courses.

Students provided numerous comments on learning success related to aspects of screencast feedback. Most comments revolved around three topics: a) enhanced transparency of grading and performance, $b$ ) the provision of knowledge as summarized by [1] ("Knowledge of response (KR)", "Knowledge of correct response (KCR)", and "Elaborated feedback (EF)"), and c) reflection on the learning process, using the provided feedback as an anchor to think about one's own or other students' learning approaches and efforts.

\section{DISCUSSION}

As a whole, the case studies in course A and course B show that screencasts can be assessed as a valuable tool to provide instructor-given feedback. The prerequisites concerning the technical infrastructure and screencast production are rather low. Thus, there are no unsurmountable hindrances on the part of feedback screencast provision. In contrast, once the initial hurdles are overcome, one can expect it to be a huge timesaver in comparison to the provision of elaborate written feedback.

Results with regard to the usage of feedback screencasts on the receivers' part are also encouraging. The present paper supports the positive views on feedback screencasts as argued in preceding case studies (cp. section III). Results indicate that feedback screencasts are accepted and exhibit positive educational benefits by fostering learning motivation and learning success for directly addressed learners.

With respect to feedback usage at an expanded social level (as argued in section IV), results are also encouraging. Nevertheless, the empirical results show that such a feedback configuration is not without problems. A substantial percentage of the participants are unsure if feedback to one group should be publicly provided to all course participants. In addition, the data indicates that it is questionable if such feedback generates positive motivational effects.

However, at the same time, the data from both case studies show that the expanded feedback circles foster learning success for all learners. Being able to use feedback on the work of other students not only exhibits a unique value proposition (in providing knowledge where there was no knowledge before), it is also on a par with feedback students receive on their own group work with regard to the stimulation of topical and metacognitive and/or procedural knowledge.

For both reasons, a feedback usage that offers opportunities to learn from feedback given to others seems to be very worthwhile. Thus, from the author's point of view, the issue of learning from feedback given to other learners seems to be a very reasonable research area that deserves further attention.

This paper should only be seen as a starting point. The results here need to be considered as explorative. The sample size in the two case studies is rather small. The research design is basic. Results are valid only in the given context and for the employed feedback configuration as a whole. Further investigations could and should refine the research design and experiment with differentiated feedback forms.

Nevertheless, the core message of the paper is clear. Screencasts can be employed as feasible and worthwhile feedback tools to give feedback to learners that are directly involved in the learning process, but also to expand feedback circles at higher social levels.

\section{REFERENCES}

[1] M. C. Heitink, B. P. Veldkamp, S. Dobson, and G. Argusti, "Deliverable 4.4 - Review effective feedback and formative assessment in e-learning," Libe (Supporting Lifelong learning with ICT Inquiry-Based Education) Project Progress Report, September 2014.

[2] E. K. Molloy and D. Boud, "Feedback models for learning, teaching and performance," Handbook of research on educational communications and technology, New York: Springer, 2014, pp. 413-424

[3] E. H. Mory, "Feedback research revisited," Handbook of Research on Educational Communications and Technology, London: Lawrence Erlbaum, 2004, pp. 745-783.

[4] N. S. Subramanian, S. Anand, and K. Bijlani, "Enhancing e-learning education with live interactive feedback system, " in Proc. the 2014 International Conference on Interdisciplinary Advances in Applied Computing, no. 53, pp. 1-7.

[5] S. Jordan, "E-assessment for learning? Exploring the potential of computer-marked assessment and computer-generated feedback, from short-answer questions to assessment analytics," Ph.D. dissertation, The Open University, 2014.

[6] M. Jara and H. Mellar, "Quality enhancement for e-learning courses: The role of student feedback," Computers \& Education, vol. 54, no.3, pp. 709-714, 2010.

[7] J. Lu and N. Law, "Online peer assessment: Effects of cognitive and affective feedback," Instructional Science, vol. 40, no. 2, pp. 257-275, 2012.

[8] K. Edwards, A.F. Dujardin, and N. Williams, "Screencast feedback for essays on a distance learning MA in professional communication," Journal of Academic Writing, vol. 2, no. 1, pp. 95-126, 2012.

[9] P. Marriott and L.K. Teoh, "Using screencasts to enhance assessment feedback: students' perceptions and preferences," Accounting Education, vol. 21, no. 6, pp. 583-598, 2012.

[10] J. Griesbaum and R. Kölle, "Screencasts as a tool for presenting students' group work results and for instructor-given feedback," DeLFI 2011: Die 9. e-Learning Fachtagung Informatik-Poster, Workshops, Kurzbeiträge, TUD Press, 2011.

[11] S. Narciss, "Feedback strategies for interactive learning tasks," Handbook of Research on Educational Communications and Technology, Mahaw, NJ: Lawrence Erlbaum, 2008, pp. 125-144.

[12] J. B. Walter, "Theories of computer-mediated communication and interpersonal relations," The Handbook of Interpersonal Communication, Austin: Sage Publications, 443-479, 2011.

[13] R. E. Mayer, "Multimedia learning: Are we asking the right questions?" Educational psychologist, vol. 32, no. 1, pp. 1-19, 1997.

[14] N. Durbridge, "Media in course design, No.9, audio cassettes," The Role of Technology in Distance Education, Kent: Croom-Helm, pp. 99-108, 1984.

[15] D. K. Griffin, D. Mitchell, and S. J. Thompson, "Podcasting by synchronising PowerPoint and voice: What are the pedagogical benefits?" Comput. Educ., vol. 53, no. 2, pp. 532-539, 2009.

[16] M. Scardamalia and C. Bereiter, "Computer support for knowledge-building communities," Journal of the Learning Sciences, vol. 3, pp. 265-283, 1994.

[17] G. Siemens. (January 2005). Connectivism: A learning theory for the digital age. International Journal of Instructional Technology and Distance Learning [Online]. Available: http://www.itdl.org/journal/jan_05/article01.htm

[18] D. R. Krathwohl, “A revision of Bloom's taxonomy: An overview," Theory into Practice, vol. 41, pp. 212-218, Autumn 2002.

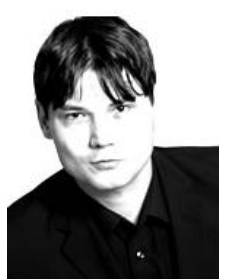

Joachim Griesbaum was born in Lahr/Schwarzwald, Germany, in 1971. He obtained his doctoral degree in information science in 2006 from the University of Konstanz in Germany. In 2008 he joined the University of Hildesheim, Germany, as an assistant professor of information science. His research interests include social media, e-learning, knowledge management, and online marketing. 